\title{
Second Language Learner Knowledge of Verb-Argument Constructions: Effects of Language Transfer and Typology
}

UTE RÖMER

Georgia State University

Department of Applied Linguistics and ESL

34 Peachtree Street, Suite 1200

Atlanta, GA 30303

Email: uroemer@gsu.edu

\author{
NICK C. ELLIS \\ University of Michigan \\ Department of Psychology \\ 530 Church Street \\ Ann Arbor, MI 48109 \\ Email: ncellis@umich.edu
}

\author{
MATTHEW BROOK O'DONNELL \\ The University of Pennsylvania \\ Annenberg School for Communication \\ 3620 Walnut Street \\ Philadelphia, PA 19104 \\ Email: mbod@asc.upenn.edu
}

\begin{abstract}
This article examines second language (L2) learner knowledge of English verb-argument constructions (VACs), for example, the 'V against $\mathrm{n}$ ' construction. It investigates to what extent constructions underpin L2 learners' linguistic competence, how VAC mental representations in native speakers and learners differ, and whether there are observable effects of the learners' first language. Native speakers of English and advanced learners of 3 different first language backgrounds (Czech, German, Spanish) were asked to generate the first verb that came to mind to fill the gap in 20 sparse VAC frames like "she __ against the...." The comparison of learner and native speaker verb responses highlights crosslinguistic transfer effects as well as effects of language typology that impact verb semantics (cf. Talmy, 1985). Our findings suggest that learners whose L1 is, like English, satellite-framed (here Czech and German) produce more target-like verbs than learners whose L1 is verb-framed (here Spanish).
\end{abstract}

Keywords: usage-based language acquisition; Construction Grammar; advanced learners; crosslinguistic influence; satellite- vs. verb-framed languages

THIS ARTICLE PRESENTS SELECTED FINDings from a large research project at the interface of Corpus Linguistics, Construction Grammar, and language acquisition. Recent work in corpus linguistics has provided ample evidence for the highly patterned nature of language (e.g., Hunston \& Francis, 2000; Römer, 2005, 2009; Sinclair,

The Modern Language Journal, 98, 4, (2014)

DOI: $10.1111 / \operatorname{modl} .12149$

0026-7902/14/952-975 \$1.50/0

(C) 2014 The Modern Language Journal
1991, 2004; Stubbs, 2001). Written texts and spoken utterances are not just random sequences of individual words that can be solely explained on the basis of grammatical rules, but are made up to a large extent of fixed or semi-fixed elements that convey meanings. Cognitive linguistic theories of construction grammar posit that language comprises many thousands of constructions: form-meaning mappings, conventionalized in the speech community, and entrenched as language knowledge in the learner's mind (Bybee, 2010; Goldberg, 1995; Robinson \& Ellis, 2008; Trousdale \& Hoffmann, 2013). 
Construction Grammar suggests a fixed correspondence between a linguistic form and its meaning and argues that combinations of words ('constructions') carry meaning as a whole (Goldberg, 2003, 2006). Psycholinguistic research demonstrates language processing to be sensitive to usage frequency across many language processes and representations: phonology and phonotactics, reading, spelling, lexis, morphosyntax, formulaic language, language comprehension, grammaticality, sentence production, and syntax (Ellis, 2002). That language users are sensitive to the input frequencies of constructions entails that they must have registered their occurrence in processing, and these frequency effects are thus compelling evidence for usage-based models of language acquisition (Bybee, 2006, 2010; Ellis, 2002; MacWhinney, 2001; Tomasello, 2003).

Second language (L2) and first language (L1) learners alike share the goal of understanding and producing language. Since they achieve this based upon their experience of language usage, there are many commonalities between L1 and L2 acquisition that can be understood from corpus analyses of speaker input and from cognitive and psycholinguistic analyses of construction acquisition following associative and cognitive principles of learning and categorization. Usage-based approaches, Cognitive Linguistics, and Corpus Linguistics are thus increasingly influential in second language acquisition (SLA) research (Collins \& Ellis, 2009; Ellis, 1998, 2003; Ellis \& Cadierno, 2009; Robinson \& Ellis, 2008). However, because L2 learners have previously devoted considerable resources to the estimation of the characteristics of their native tongue in which they have become fluent, their computations and inductions are often affected by transfer, with L1-tuned expectations and selective attention (Ellis, 2006; Ellis \& Sagarra, 2011) blinding the acquisition system to aspects of the L2 sample. Learned attentional biases from various L1s may influence the ultimate language attainment of L2 learners from various L1 backgrounds (Ellis \& Sagarra, 2011). SLA is thus different from first language acquisition in that it involves processes of construction and reconstruction. We explore these issues in this article.

In a collaborative project among psycho-, corpus-, and computational linguists, we study speaker knowledge and use of English verbargument constructions (henceforth VACs), such as the ' $\mathrm{V}$ against $\mathrm{n}$ ' construction (e.g., he leaned against the door frame) or the ' $\mathrm{V} \mathrm{n} \mathrm{n}$ ' construction (e.g., they sent her a letter). Small sets of VACs have been analyzed in native and learner corpora in order to determine regularities in their acquisition and use (Ellis \& Ferreira-Junior, 2009; Goldberg, 2006; Goldberg, Casenhiser, \& Sethuraman, 2004; Ibbotson, 2013). These studies conclude that there is a strong tendency for one single verb to occur with particularly high frequency in comparison to other verbs and that the overall distribution of verbs in constructions follows Zipf's (1935) law, which states that the frequency of words decreases as a power function of their ranks in the frequency table. The studies show how the frequencies of verbs influence acquisition, and how Zipfian distributional properties of language usage help make language learnable, for both first and second language learners. The findings are revealing but have yet to be backed up by evidence from more constructions and larger datasets. Also needed is experimental data on what speakers of English know about the verbs that occur in particular VACs. Evidence on speaker knowledge of VACs will help us determine whether constructions are psychologically real and how strongly they are entrenched in the speaker's mind.

We have taken a large sample of 50 constructions, identified and discussed in COBUILD Grammar Patterns 1: Verbs (Francis, Hunston, \& Manning, 1996), as a starting point for a systematic analysis of VACs in the 100-million word British National Corpus (BNC). In Römer, O'Donnell, \& Ellis (2015), we describe the steps involved in mining the BNC for VACs and suggest a new approach to making verb construction analyses scalable. We have also carried out psycholinguistic experiments to capture native speaker and nonnative speaker associations of verbs and the selected constructions. In Ellis, O'Donnell, \& Römer (2014a), we use generative free association tasks to test the psychological reality of VACs in terms of their form-function representation, type-token distribution, verbconstruction contingency, and semantic structure. In one experiment, 285 native English speakers generated the first word that came to mind to fill the verb slot in 20 sparse VAC frames such as 'she __ across the...' In another experiment, 40 native English speakers generated as many verbs fitting each VAC frame as they could think of in a minute. Through our largescale corpus analyses (based on the BNC), we demonstrated the reliability and validity of VACs in language usage. We found that verb constructions are (a) Zipfian in their type-token distributions, with one verb type accounting for the lion's share of all VAC tokens, (b) selective in their verb form occupancy, and (c) coherent in their 
semantics (for details, see Ellis, O'Donnell, \& Römer, 2013; Römer et al., 2015). Through our psycholinguistic experiments, we demonstrated the reliability and validity of VACs in language users' minds. We observed that adult native speakers of English represented similar bindings of form and function as retrieved from usage data. The verbs produced by fluent language users are determined by (a) their token frequencies in the respective VAC in usage, (b) how faithful verbs are to particular VACs in usage, and (c) the centrality of the verb meaning in the VAC's semantic network in usage (for details, see Ellis et al., 2014a).

Following the empirical design and methodology described in Ellis et al. (2014a) and Römer et al. (2015), we have also used corpus- and psycholinguistic evidence to measure second language learner knowledge of VACs. We were interested in finding out whether, and to what extent, constructions also underpin L2 learners' linguistic competence. We were also interested in determining how similar or different the mental representations of common VACs are between native speakers and learners of English and whether there are observable effects of the learners' first language. We had English native speakers and advanced English language learners of three different first language backgrounds (German, Czech, and Spanish) complete the same type of free association task (details provided in the Data and Method section) and compared responses across those four groups. We correlated the results from these association tasks (for L1 and L2 speakers) with results from large-scale corpus analyses of the same VACs. We found that learners have strong constructional knowledge and that, similar to native speakers, the VAC processing of L1 German, Czech, and Spanish advanced learners of English, too, showed effects of frequency, contingency, and prototypicality. These findings are discussed in Ellis, O'Donnell, \& Römer (2014b). Our discussion highlights similarities in the patterns that underlie both first and second language VAC acquisition. Our findings reflect L2 knowledge of language that comes from usage and indicate that all groups of participants are sensitive to distributions in the language they are exposed to, albeit to varying extents.

One thing that Ellis et al. (2014b) does not discuss is in what ways native speaker mental representations differ from those of advanced language learners. It also does not provide details on potential crosslinguistic transfer (Jarvis, 2013; Odlin, 2013) from German, Czech, or Spanish. A central aim of our present article is to uncover and discuss these differences and transfer effects in order to better understand which realizations of which VACs are not, or not yet, well entrenched in the minds of learners, and which ones are. In the discussion of differences between native speaker and learner knowledge of VACs, we consider issues of language typology that affect the verb system, particularly the semantics of verbs. A useful typological distinction, introduced by Talmy $(1985,1991,2000)$, can be made between verb-framed and satellite-framed languages, which differ in how they encode the path and manner of motion within the verb phrase. We will provide an overview of these concepts in the following section of this article, followed by a summary of our research questions and hypotheses. We will then describe the design and implementation of the psycholinguistic experiments carried out for this study, and summarize the data retrieval and evaluation steps. The core section of the article is dedicated to the discussion of results on speaker knowledge of 20 selected VACs. We will end with a summary of main findings, implications for instruction, and further directions for related research.

\section{LANGUAGE TYPOLOGY: VERB-FRAMED AND SATELLITE-FRAMED LANGUAGES}

Languages differ in the ways in which verb phrases express motion events. According to Talmy (2000),

the world's languages generally seem to divide into a two-category typology on the basis of the characteristic pattern in which the conceptual structure of the macro-event is mapped onto syntactic structure. To characterize it initially in broad strokes, the typology consists of whether the core schema is expressed by the main verb or by the satellite. (p. 221)

The core schema here refers to the framing event, that is, to the expression of the path of motion. Talmy goes on to say that "[1]anguages that characteristically map the core schema into the verb will be said to have a framing verb and to be verb-framed languages" and that "languages that characteristically map the core schema onto the satellite will be said to have a framing satellite and to be satellite-framed languages" (p. 222; emphasis in original). Included in the former group are Romance and Semitic languages, Japanese, and Tamil. Languages in the latter group include Germanic, Slavic, Finno-Ugric languages, and Chinese. This means that a Germanic language 
such as English often uses a combination of verb plus preposition or particle (go into, jump over) where a Romance language like Spanish uses a single form (entrar, saltar).

While verb-framed languages express the path of motion in the main verb and are pathincorporating (Talmy, 1985) or path-type languages (Mani \& Pustejovski, 2012), satellite-framed languages are manner-incorporating or manner-type languages in which manner is expressed in the main verb (e.g., English run, stroll). According to Slobin (2003, p. 162), "English speakers get manner for free." They commonly use manner verbs in the expression of motion events and have more lexical items available to do so than speakers of satellite-framed languages like Spanish. The Spanish motion verb saltar, for example, has a range of English translation equivalents including jump (over, up), leap, climb, skip, spurt, and hop. Manner of motion is a "highly saturated" semantic space in satellite-framed languages (Slobin, 2003, p. 163). In verb-framed languages, manner of motion is less commonly expressed. It is "an adjunct-an optional addition to a clause that is already complete" (Slobin, 2003, p. 162), such as a participial form (e.g., Spanish entró corriendo, "enter running"). We therefore assume manner of motion to be a less entrenched, less salient concept in the minds of speakers whose L1 is verbframed. The concept is less easily codable and requires additional effort to express. CifuentesFérez and Gentner (2006) provide empirical evidence in support of this assumption by showing that, in a word mapping task, Spanish speakers were more likely to infer a path interpretation of a novel motion verb than a manner interpretation. English speakers showed the opposite behavior and favored manner over path interpretations (see Brown \& Gullberg, 2011; Cadierno, 2008, 2013; and Slobin, 2003, 2006, for reviews of additional studies that demonstrate similar effects of language typology on linguistic production). Whereas Slavic languages are generally considered satellite-framed (Slobin, 2003, 2006), Gehrke (2008) cautions that Czech is "neither straightforwardly verb-framed nor straightforwardly satellite-framed" (p. 203). While motion and manner in Czech are included in the verb (as is typically the case for a satellite-framed language), paths of motion may be mapped onto the verb and/or a directional preposition. To give one example, Czech offers three ways of expressing jump over: skočit přes ('jump over'), přeskočit pres ('overjump over'), and preskočit ('overjump'). Czech hence appears to be a less prototypical satellite-framed language than English or Ger- man. This observation is incorporated in the discussion of our survey results.

\section{RESEARCH QUESTIONS AND HYPOTHESES}

The research questions we are addressing in this article are:

RQ1. Following from the observation that constructions underpin L2 learners' linguistic competence (Ellis et al., 2014b), how similar or different are the existing mental representations of common VACs between advanced L2 learners and native speakers?

RQ2. Are there observable differences in the mental representations of common VACs among L1 German, L1 Czech, and L1 Spanish learners? Is one learner group closer to the native speaker group than the others?

RQ3. If there are such differences, can they be explained on the basis of transfer from the learners' first languages and/or on the basis of language typology effects?

All groups of speakers in our study are asked to produce verbs in response to VAC frames the majority of which encode a path of motion, with the path expressed by a satellite (a particle or preposition). Against the background of the language-typological issues discussed in the previous paragraphs, our research hypotheses (H) are:

H1. The mental VAC representations of German, Czech, and Spanish advanced learners of English will differ in diverse ways from native speakers' mental VAC representations, showing that learners are biased by their L1s.

H2. Learners whose L1 is satellite-framed (and hence typologically similar to English) will produce more target-like verbs (verbs that correlate more closely with those produced by L1 English speakers) than speakers whose L1 is verb-framed.

H3. Speakers of satellite-framed languages (here German and Czech, even though the latter is not a clear-cut case) will produce more verbs that express specific manners of motion in the verb generation tasks (in line with native speakers).

H4. Conversely, speakers of a verb-framed language (here Spanish) will produce specific 
manner of motion verbs less frequently and instead respond with more general motion verbs such as GO, COME, or MOVE.

H5. The verb responses of all learner groups will show effects of collocational transfer (Yamashita \& Jiang, 2010) from the learners' first languages.

We will refer back to these hypotheses in our results discussion and conclusion.

\section{DATA AND METHOD}

The data collected for this study come from a series of psycholinguistic experiments administered online using the Qualtrics survey system. ${ }^{1}$ Native English speakers and German, Czech, and Spanish advanced learners of English (described in more detail later) completed the same generative free association task that presented them with VAC frames such as 'she off the...' or 'it over the...' and asked them to type the first word that came to mind to fill the blank. Free association tasks like this are standard in psychology for determining which items are most closely associated with a particular category (Battig \& Montague, 1969; Rosch \& Mervis, 1975). The actual instructions that participants received are given in Figure 1. After the survey instructions, the participants saw the 20 sentence frames displayed in Table 1, shown once with either she or he as subject and once with $i t$ as subject. These 40 prompts were presented in random order and participants filled the gaps in each frame. For each VAC, we recorded the verbs produced and the participants' response times. The entire survey took between 5 and 15 minutes to complete. $^{2}$

The participants were predominantly university students recruited through emails sent by members or associates of the research team, either to the students directly or (in the case of the learners who participated) to one of their instructors. The English native speakers were mostly students enrolled at a large Midwestern research university. The L1 German, L1 Czech, and L1 Spanish learners were students enrolled at research universities in Germany, the Czech Republic, and Spain, respectively. The learners in all three groups had been in instructed EFL settings in Germany, the Czech Republic, or Spain for at least

\section{FIGURE 1}

Instructions Given to Participants at the Beginning of the Online Survey

We are studying how people use English verbs. We are going to show you a phrase with a verb

missing and ask you to fill in the gap with the first word that comes to your mind.

For example, for the phrase:

he her the...

you might respond

he gave her the... or he sends her the ...

And for the phrase:

it down the ...

you might respond

it rolls down the ... or it fell down the ...

On each page you will be presented with a phrase like one of these with a line indicating a missing word. In the text box, type the first word that you think of and press the [ENTER] key. 
TABLE 1

Selected Verb-Argument Constructions (VACs) and Prompts Used in Experiments

\begin{tabular}{|c|c|}
\hline Selected VACs & Survey Prompts \\
\hline $\mathrm{V}$ about $\mathrm{n}$ & he $\_$about the...; it __ about the... \\
\hline $\mathrm{V}$ across $\mathrm{n}$ & she $\_$across the...; it __ across the... \\
\hline $\mathrm{V}$ after $\mathrm{n}$ & he $\_$after the...; it __ after the... \\
\hline $\mathrm{V}$ against $\mathrm{n}$ & she $\_$against the...; it __ against the... \\
\hline $\mathrm{V}$ among $\mathrm{n}$ & she __ among the...; it __ among the... \\
\hline $\mathrm{V}$ around $\mathrm{n}$ & he $\_$around the...; it __ around the... \\
\hline $\mathrm{V}$ as $\mathrm{n}$ & she $\ldots$ as the...; it __ as the... \\
\hline $\mathrm{V}$ at $\mathrm{n}^{2}$ & he $\_$at the...; it $\_$at the... \\
\hline $\mathrm{V}$ between $\mathrm{n}$ & he __ between the...; it __ between the... \\
\hline $\mathrm{V}$ for $\mathrm{n}$ & she __ for the...; it __ for the... \\
\hline $\mathrm{V}$ in $\mathrm{n}$ & he $\_$in the...; it $\_$in the... \\
\hline $\mathrm{V}$ into $\mathrm{n}$ & she $\_$into the...; it __ into the... \\
\hline $\mathrm{V}$ like $\mathrm{n}$ & he $\ldots$ like the...; it __ like the... \\
\hline $\mathrm{V}$ of $\mathrm{n}$ & he $\_$of the...; it __ of the... \\
\hline $\mathrm{V}$ off $\mathrm{n}$ & she $\_$off the...; it ___ off the... \\
\hline $\mathrm{V}$ over $\mathrm{n}$ & she __ over the...; it __ over the... \\
\hline $\mathrm{V}$ through $\mathrm{n}$ & he _ through the...; it __ through the... \\
\hline $\mathrm{V}$ towards $\mathrm{n}$ & she __ towards the...; it __ towards the... \\
\hline $\mathrm{V}$ under $\mathrm{n}$ & he $\_$under the...; it $\_$under the... \\
\hline $\mathrm{V}$ with $\mathrm{n}$ & she __ with the...; it __ with the... \\
\hline
\end{tabular}

7 years. The mean number of years of formal English instruction was 10.04 years for German, 11.37 for Czech, and 12.68 for Spanish learners. According to their instructors, the proficiency levels of the German and Czech learners corresponded to level $\mathrm{C} 1$ in the Common European Framework of Reference for Languages (CEFR), described as the "Effective Operational Proficiency" level (Council of Europe, 2001). Our Spanish contacts reported that the majority of students who participated in the survey were advanced learners at CEFR level $\mathrm{C} 1$ while some of them (an estimated 10\%) were at level B2 ("Vantage" level). Our contacts confirmed that they did not share the survey link with learners at lower levels of proficiency.

The following numbers of participants volunteered to complete the VAC survey: 285 native English speakers, 276 L1 German learners of English, 185 L1 Czech learners of English, and 131 L1 Spanish learners of English. To ensure comparability across datasets, we based our analyses on only 131 responses from each of the four participant groups, including all of the L1 Spanish responses and 131 randomly selected responses each from the native speaker, L1 German, and L1 Czech groups. For each group, the lists of responses were lemmatized by verb type (e.g., runs, ran, was running etc. $\rightarrow$ RUN) and ordered by verb token frequencies. ${ }^{3}$ We then carried out comparisons of lists based on the learner responses with lists based on English native speaker responses: L1 German vs. English, L1 Czech vs. English, and L1 Spanish vs. English. We used a simple regression general linear model (GLM) framework to build models for each of these language pairings for each of the 19 VACs. We used R (R Development Core Team, 2012) to perform statistical analyses of the data. Verb frequency in the English sample was taken as a proxy for native speaker VAC knowledge (i.e., this is what a native speaker says confronted with the VAC frame) and was used as the single predictor of verb frequency in the L1 German, Czech, and Spanish samples. Frequencies were $\log$ transformed due to the Zipfian nature of the distribution (i.e., a long-tailed distribution, see Tables 3 to 5) to bring them into linear space for the comparison of the two L1 distributions. Nonoccurrence (i.e., zero frequency) of a verb in one L1 background sample that occurs in the other (e.g., none of the 131 native speakers used ARGUE in the ' $\mathrm{V}$ against $\mathrm{n}$ ' frame but 5 of the German L1 speakers did) becomes an issue because the logarithm of zero is not defined. It is, however, important to include instances such as ARGUE and SIT (5 occurrences in native speaker responses and none in L1 German) in the 'V against n' comparison of L1 German responses to native speaker responses as they contribute to the overall shape of the distribution which we take as a proxy for speaker knowledge of the VAC. Therefore, 
when computing the correlations and plotting these items, we use the $\log$ value -0.1 . We examined the correspondence between the verb frequency distributions of paired languages using a simple regression framework where verb frequency in learner responses (i.e., L1 German, Czech, or Spanish) within a specific VAC is taken as the dependent variable and frequency in native speaker responses as the independent (predictor) variable. ${ }^{4}$ We used the standardized residuals; that is, the amount of divergence between the predicted and actual values. While residuals are commonly used in regression analysis as a way of identifying outliers in the data that may be overly influencing the model or leading to a poor fit, we use them here on an item-based level as an indicator of the over- or underuse of a verb by a nonnative speaker compared to the native norm. The basic insight behind this method is that a statistical model can be built based on empirical data gathered from native speakers and be thought of as a model of "what would a native speaker do?" This model can then be used to predict the responses for nonnative speakers. The predicted and the actual values can be compared both across the whole distribution (i.e., correlation) and on an item-based level (i.e., residuals) to look at under-and overuse of specific items and to identify potential areas of L1 interference and influence.

\section{RESULTS: COMPARING NATIVE AND NONNATIVE SPEAKER VAC KNOWLEDGE}

Our discussion of results from the verb list comparisons begins with an overview of correlations between the native speaker and learner responses for the VACs listed in Table 1. For each VAC and each comparison (L1 German vs. English, L1 Czech vs. English, L1 Spanish vs. English), we also report which verbs have particularly high (positive and negative) standardized residuals and are unusually frequent or infrequent in the learner responses compared to the native speaker responses. This overview of results for all VACs is followed by a detailed analysis of three VACs that have been selected to provide us with a more in-depth picture of potential L1 transfer effects and effects of language typology on the learners' survey responses. The selected VACs are 'V against $\mathrm{n}$, ' 'V in $\mathrm{n}$,' and 'V over $\mathrm{n}$.'

\section{Overview of VACs}

Table 2 shows the overall correlations between learner and native speaker responses to the survey prompts listed in Table 1. Figure 2 provides a visual representation of these correlations, with data points represented by prepositions. The possible range of values is 0 to 1 . The closer the value is to 1 , the stronger the correlation between

TABLE 2

Correlations Between Learner and Native Speaker Responses ( $n=131$ per Group)

\begin{tabular}{lccc}
\hline \hline VAC & L1 German & L1 Czech & L1 Spanish \\
\hline V about $\mathrm{n}$ & 0.81 & 0.78 & 0.75 \\
V across $\mathrm{n}$ & 0.84 & 0.73 & 0.78 \\
V after $\mathrm{n}$ & 0.77 & 0.69 & 0.62 \\
V against $\mathrm{n}$ & 0.62 & 0.54 & 0.55 \\
V among $\mathrm{n}$ & 0.63 & 0.30 & 0.47 \\
V around $\mathrm{n}$ & 0.82 & 0.76 & 0.75 \\
V as $\mathrm{n}$ & 0.62 & 0.40 & 0.40 \\
V between $\mathrm{n}$ & 0.63 & 0.68 & 0.57 \\
V for $\mathrm{n}$ & 0.72 & 0.78 & 0.72 \\
V in $\mathrm{n}$ & 0.79 & 0.69 & 0.35 \\
V into $\mathrm{n}$ & 0.86 & 0.89 & 0.70 \\
V like $\mathrm{n}$ & 0.72 & 0.68 & 0.70 \\
V of $\mathrm{n}$ & 0.76 & 0.73 & 0.71 \\
V off $\mathrm{n}$ & 0.83 & 0.69 & 0.56 \\
V over $\mathrm{n}$ & 0.72 & 0.76 & 0.48 \\
V through $\mathrm{n}$ & 0.81 & 0.67 & 0.62 \\
V towards $\mathrm{n}$ & 0.90 & 0.80 & 0.81 \\
V under $\mathrm{n}$ & 0.71 & 0.75 & 0.70 \\
V with $\mathrm{n}$ & 0.73 & 0.60 & 0.58 \\
& Average: 0.75 & Average: 0.68 & Average: \\
\hline
\end{tabular}


FIGURE 2

Visual Representation of Correlations Between Learner and Native Speaker Responses

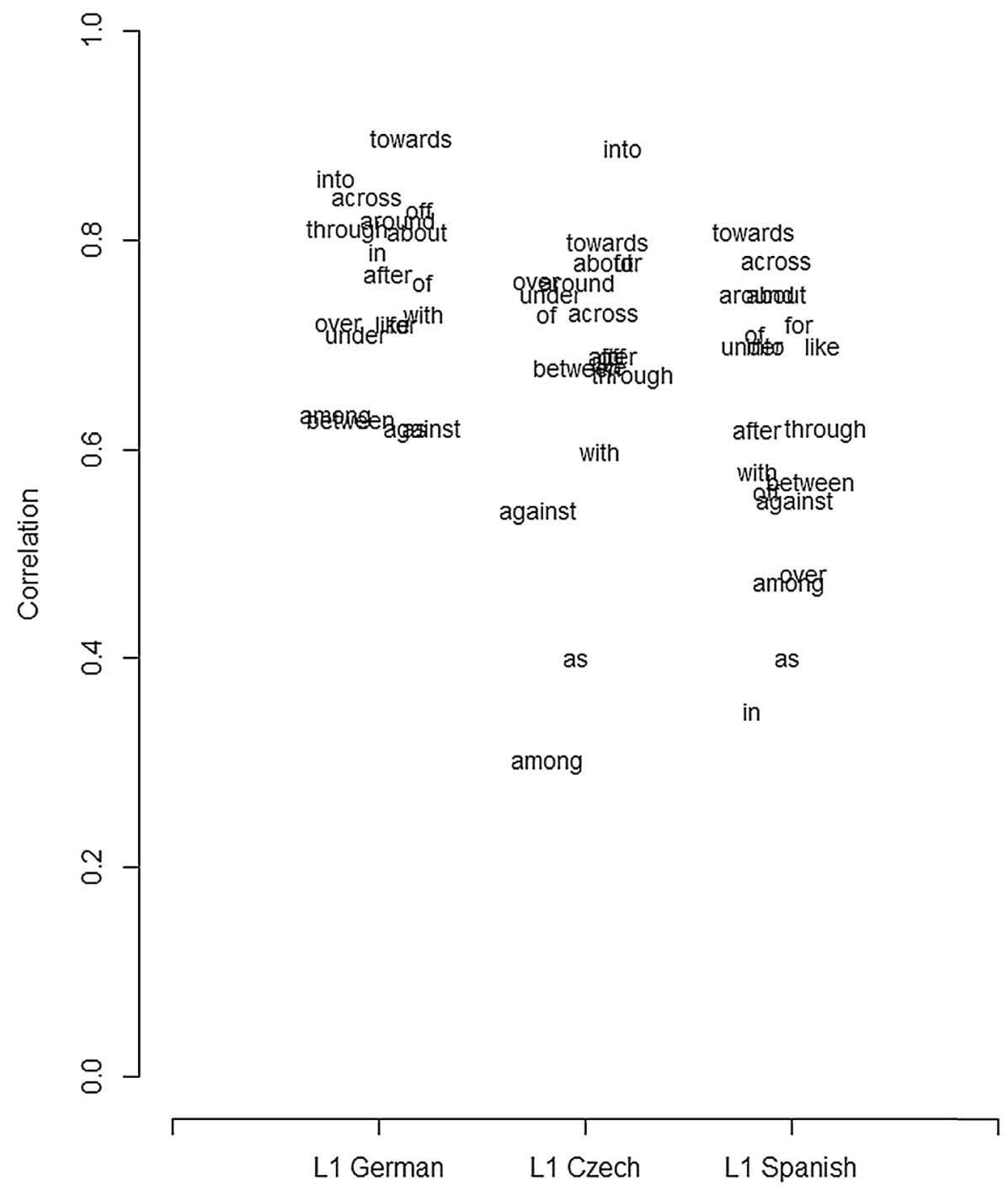

the responses. Correlation figures express how much the sets of verbs produced by a group of learners (both in terms of types and tokens) overlap with the sets of verbs produced by the group of native speakers in response to the same VAC prompt. Figure 3 provides three graphs that illustrate this comparison of the verb responses given by German/Czech/Spanish learners and native speakers for one of the selected VACs: 'V in n.' The x-axis shows the logarithmic frequency of the verb type in the native speakers' responses; the y-axis shows the logarithmic frequency of the verb type in the L2 learners' responses. If there were perfect overlap in verb responses between two groups (i.e., a correlation of 1), all verb labels would be neatly placed along the diagonal through the middle of the graph. This is not the case in any of our three comparisons. Instead, verbs are scattered to the left and right of the diagonal in all three graphs. Verbs that appear to the left of (or above) the diagonal are markedly more frequent in the learner than the native speaker responses; verbs that appear to the right of (or below) the diagonal are markedly less frequent in the learner than the native speaker responses. In the right hand scatterplot panel in Figure 3 (L1 Spanish vs. native speakers), most verbs are much farther away from the diagonal 
FIGURE 3

Correlations of Verb Responses Between Three Groups of Learner Responses (L1 German, left panel; L1 Czech, middle panel; L1 Spanish, right panel) and Native Speaker Responses (L1 English) for 'V in n'

IN (L1 German vs L1 English )

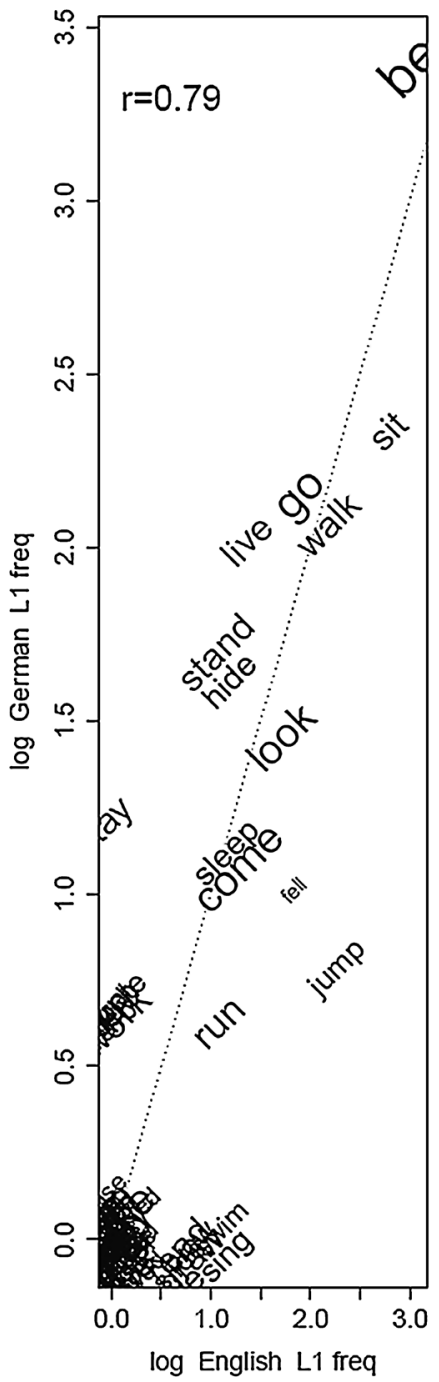

IN (L1 Czech vs L1 English)

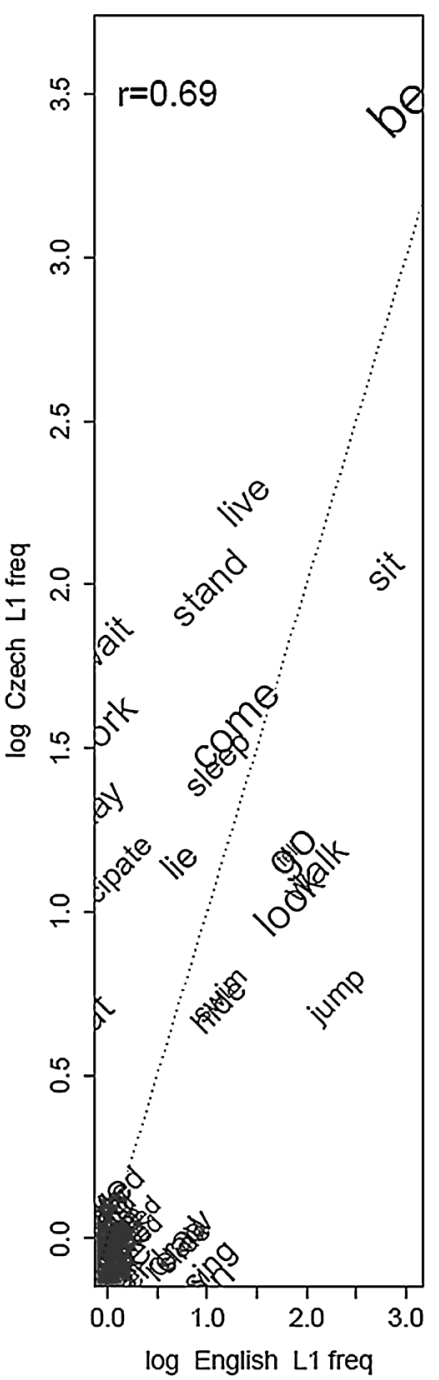

IN (L1 Spanish vs L1 English )

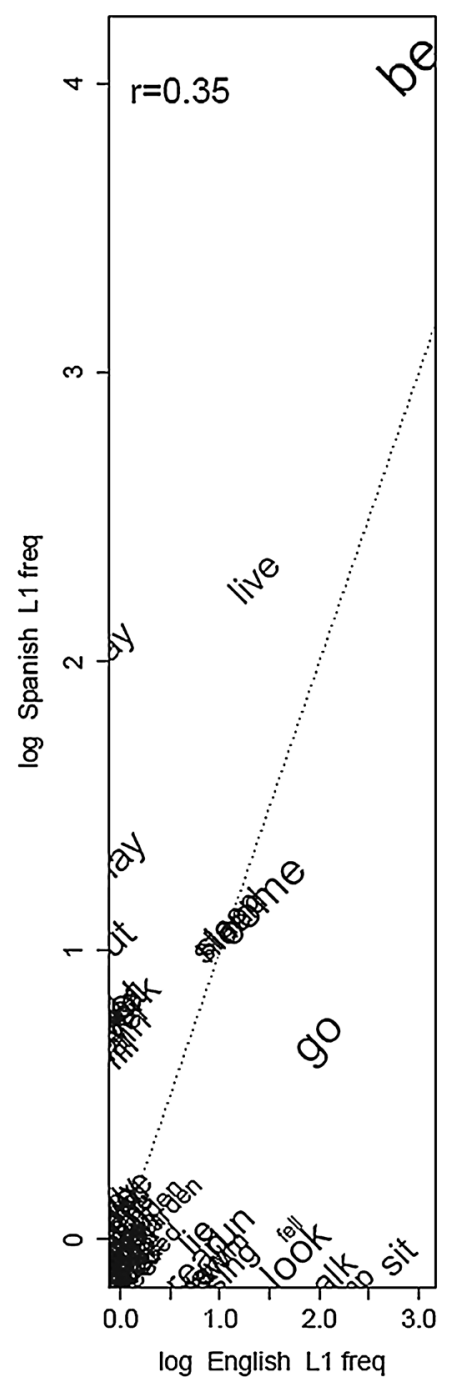

than in the middle (L1 Czech) and left panels (L1 German). L1 Spanish learners respond with verbs to this VAC that are quite different from those produced by native speakers. For example, these learners produce BE, LIVE, and STAY comparatively more often and GO, LOOK, and SIT comparatively less often than native speakers. This lack of overlap is reflected in the rather low correlation figure of 0.35 (compared to values of 0.69 and 0.79 for Czech and German).

Across the 57 datasets captured in Table 2 and Figure 2 (19 VACs times three learner groups), correlations range from 0.3 ('V among n,' L1
Czech) to 0.9 ('V towards n,' L1 German). As Figure 2 indicates, L1 German vs. English correlations are much more homogeneous across VACs (0.62 to 0.9$)$ than L1 Spanish vs. English and (even more so) L1 Czech vs. English correlations ( 0.35 to 0.81 and 0.3 to 0.89 respectively) ${ }^{5}$ For L1 German, we also observe a higher average correlation of 0.75 than for L1 Czech (0.68) and L1 Spanish (0.62). None of the L1 German vs. English correlations falls below 0.6 , whereas three of the L1 Czech correlations (for 'V against $\mathrm{n}$,' 'V amongn,' and 'V as n') and eight of the L1 Spanish correlations do (for 'V againstn,' 'V amongn,' 'V as 
$\mathrm{n}$,' 'V between $\mathrm{n}$, ' 'V in $\mathrm{n}$, ' 'V offn,' 'V over $\mathrm{n}$,' and 'V with n'). This means that, overall, the German learner responses most closely and the Spanish learner responses least closely match the native speaker responses, with the Czech learner responses falling somewhere between these two groups (see our earlier comments on Czech's status as a less clear-cut exemplar of a satelliteframed language). It appears that, at least with respect to a large number of VACs, Spanish learners' form-meaning mappings are less in line with native speaker peers than those of German or Czech learners, confirming our Hypothesis 1, which predicted that our different learner groups would differ from the native speaker group in diverse ways. This is particularly true for the VACs 'V against $\mathrm{n}$, ' 'V among $\mathrm{n}$, ' 'V as $\mathrm{n}$, ' 'V between $\mathrm{n}$, ' 'V in n,' 'V offn,' 'V overn,' and 'V withn,' all of which have below average correlations (see "L1 Spanish" column in Table 2). The corresponding correlations for L1 German and L1 Czech tend to be higher, often considerably so (with the exception of ' $\mathrm{V}$ among n' and ' $\mathrm{V}$ as $\mathrm{n}$ ' in the L1 Czech dataset). We will investigate a selection of these VACs and related learner verb preferences in more detail in the following sections. This confirms our Hypothesis 2, predicting that Spanish learners find it harder than German and Czech learners to produce verbs that correlate closely with those produced by native English speakers.

Our analysis of standardized residuals aimed at highlighting verbs that are either particularly common in the learner responses (high positive standardized residuals) or particularly rare in or absent from the learner responses (high negative standardized residuals), always in comparison with the native speaker responses to the same VAC frames. We consider residuals that fall outside of +2 or -2 standard deviations unusual and include the corresponding verbs and absolute response token frequencies in the table in Appendix A. To facilitate data interpretation, we use gray shading for verbs with negative standardized residuals below -2 . We are interested in verb selection patterns that emerge across VACs and across L1s. In line with Hypotheses 3 and 4, we expect that, in their verb responses to VAC frames that serve to express directed motion events, Spanish learners of English will indicate manner of motion less often than native English speakers and German and Czech learners do. Instead, we expect Spanish learners to overuse general motion verbs that do not express a specific manner.
Appendix A indicates a number of verb preferences that are shared across the three learner groups. Verbs that are produced significantly more frequently by learners in all groups than by native speakers are: COME for ' $\mathrm{V}$ across $\mathrm{n}$ ' and 'V towards n'; LOOK for ' $\mathrm{V}$ after n,' 'V as n,' and 'V inton'; BE for 'V against $\mathrm{n}$ ' and 'V amongn'; MOVE for ' $\mathrm{V}$ around n'; STAY, BE, and LIVE for ' $\mathrm{V}$ in n'; and STAY for 'V with n.' All of these verbs have high frequencies in general English language use and appear to be highly entrenched in the learners' minds. Appendix A also indicates that a large number of verbs with high positive standardized residuals are not shared by learners of different L1 backgrounds. To give a few examples: THINK is overused by German learners in response to the 'V about n' frame but not by Czech and Spanish learners who favor SPEAK instead. For 'V among n,' German learners show strong associations with COME and STAND, Czech learners with BELONG and STAND, and Spanish learners with APPEAR and GO. For ' $\mathrm{V}$ through n,' the verbs with the highest positive residuals are WALK and CLIMB for German learners, GET and SEE for Czech learners, and GO and PASS for Spanish learners.

The verb GO is a particularly interesting case. GO appears in the L1 Spanish positive standardized residuals lists for 7 out of 19 VACs. Responding to a VAC frame with a form of this verb appears to be a productive strategy for the Spanish survey participants. Other general motion verbs that are overused by L1 Spanish learners are COME and моve. The Spanish learners in our study seem to favor these general verbs (especially GO) over more specific manner of motion verbs that appear in the negative standardized residuals lists (e.g., JUMP, RUN, CRAWL, SLIP). The German and Czech learners also overuse general motion verbs with individual VACs but not as often as the Spanish learners. The verb Go appears in two of the German and four of the Czech positive standardized residuals lists. This is evidence in support of our Hypotheses 3 and 4, predicting that Spanish learners will indicate manner of motion less often than native English speakers and German and Czech learners will. Our finding is in line with Cadierno's (2010) observation that beginning to intermediate L1 Spanish learners of Danish (like English, a satellite-framed language) did not produce specific manner of motion verbs in a production task but instead overgeneralized and used Gå (GO, wALK) in all walking-related contexts whereas Russian and German learners of Danish employed more manner of motion verbs. Another interesting pattern is the occurrence of $\mathrm{BE}$ in the positive residuals lists for a number of VACs. This 
applies to all three learner groups, although to a much larger extent to Spanish than German and Czech learners. BE is among the significantly overused verbs in Spanish learner responses to 12 VACs including 'V around $\mathrm{n}$,' 'V between $\mathrm{n}$,' 'V towards $\mathrm{n}$,' and 'V under n' (compared to only six VACs in the German and five VACs in the Czech datasets). This provides additional support for our Hypothesis 2. Spanish learners find it more difficult to retrieve specific target-like lexical verbs when confronted with bare VAC frames of the 's/he ___ preposition' kind than German and Czech learners do. Instead, they often opt for forms of the semantically bleached verb BE.

Even more evidence in support of (especially Spanish) learners' avoidance of specific motion verbs in the free association task can be found in the negative standardized residuals included in Appendix A (shaded gray). While there is considerable variation across L1 groups (and across VACs) with respect to underused verbs, a common feature of many of the verbs with high negative standardized residuals is that they are less frequent in general English language use than most of the overused verbs discussed in the previous paragraphs. Examples include REVOLVE and CIRCLE ('V around n'), SLIP and FALL ('V between n'), REACH ('V forn'), BUMP ('V inton'), sWIM ('V like n'), HOP 'V over n'), and CRAWL ('V under n'). Compared to the native English speakers, the advanced learners who participated in our study rely less on specific, lower frequency verbs and more on general, high-frequency verbs (see also Römer et al., 2015). We will comment more on particular differences between learner and native speaker VAC responses in the following sections.

\section{Zooming in on ' $V$ Against $N$ '}

' $\mathrm{V}$ against $\mathrm{n}$ ' is a VAC with particularly low correlation values. Correlations are below average for all three L1s ( 0.62 for German, 0.54 for Czech, and 0.55 for Spanish). We therefore expect to find considerable variation in verb choices between native speaker and learner responses (in terms of verb types, verb token numbers, or both). Table 3 shows lemmatized lists of the 20 most frequent verbs produced by the four groups of survey participants in response to the prompts 'she __ against the ...' and 'it ___ against the ....' The native speaker responses in the left hand column (shaded gray) serve as a reference point for comparisons with the German, Czech, and Spanish learner responses. Verbs are italicized in a learner list if they also appear in the native speaker list.

Of the 20 verbs most often produced by L1 German survey participants, 10 are shared with the native speaker list. While this may indicate considerable overlap, the actual token numbers and rank positions of these verbs are rather different. The verbs BE, FIGHT, and HIT, for

TABLE 3

'V Against n,' Top 20 Verbs in Native Speaker and Learner Responses

\begin{tabular}{|c|c|c|c|c|c|c|c|c|}
\hline \multirow{2}{*}{$\frac{\text { Rank }}{1}$} & \multicolumn{2}{|c|}{ Native Speakers } & \multicolumn{2}{|c|}{ German Learners } & \multicolumn{2}{|c|}{ Czech Learners } & \multicolumn{2}{|c|}{ Spanish Learners } \\
\hline & LEAN & 23 & $B E$ & 29 & FIGHT & 27 & FIGHT & 40 \\
\hline 2 & PUSH & 13 & $L E A N$ & 14 & $B E$ & 25 & $B E$ & 31 \\
\hline 3 & $\mathrm{BE}$ & 13 & FIGHT & 12 & SPEAK & 12 & STAND & 5 \\
\hline 4 & FALL & 12 & $R U N$ & 12 & $L E A N$ & 11 & PLAY & 5 \\
\hline 5 & RUN & 10 & $H I T$ & 8 & STAND & 9 & GO & 5 \\
\hline 6 & GO & 10 & $F A L L$ & 7 & VOTE & 6 & $L E A N$ & 4 \\
\hline 7 & FIGHT & 6 & ARGUE & 5 & PUSH & 5 & ARGUE & 3 \\
\hline 8 & RAG & 5 & VOTE & 5 & $R U N$ & 5 & $F A L L$ & 3 \\
\hline 9 & SIT & 4 & REBEL & 4 & $G O$ & 5 & SPEAK & 2 \\
\hline 10 & PROTEST & 3 & GO & 3 & PROTEST & 4 & PUSH & 2 \\
\hline 11 & WORK & 3 & WALK & 3 & ARGUE & 3 & REACT & 2 \\
\hline 12 & HIT & 3 & DEMONSTRATE & 3 & RISE & 2 & $R U N$ & 2 \\
\hline 13 & RISE & 2 & KICK & 2 & COME & 2 & CRASH & 2 \\
\hline 14 & RAIL & 2 & CRASH & 2 & MOVE & 2 & STAY & 2 \\
\hline 15 & REST & 2 & PROTEST & 1 & OBJECT & 1 & SAVE & 1 \\
\hline 16 & CROUCH & 1 & RISE & 1 & TURN & 1 & CHANGE & 1 \\
\hline 17 & STRUGGLE & 1 & WORK & 1 & SAY & 1 & CAN & 1 \\
\hline 18 & RAM & 1 & SPEAK & 1 & ROLL & 1 & CLAIM & 1 \\
\hline 19 & BUMP & 1 & SHOUT & 1 & DECIDE & 1 & DISCUSS & 1 \\
\hline 20 & FLY & 1 & STUMBLE & 1 & $H I T$ & 1 & PLACE & 1 \\
\hline
\end{tabular}

Note. Italicized verbs indicate overlap between a learner list and the native speaker list. 
instance, are more frequent in the German learner than the native speaker responses, whereas native speakers more often produce forms of LEAN, FALL, and GO in response to against frames. The two lists suggest that native speakers and German learners have different semantic associations with this VAC. Native speakers associate verbs that express (forced) physical contact or collision with ' $\mathrm{V}$ against $\mathrm{n}$,' especially the topranked LEAN (23 instances) and PUSH (13 instances; not in the German list), but also the less frequent SIT, REST, RAM, BUMP, and FLY that do not appear in the learner list. German learners show weaker associations with these verbs and instead produce verbs that express a (mostly verbal) reaction or argument, including FIGHT, ARGUE, VOTE, REBEL, DEMONSTRATE, SPEAK, and ShOUT. A possible explanation for this semantic preference is crosslinguistic transfer from German where the verbs KäMPFEN ('FIGHT'), PROTESTIEREN ('PROTEST'), VOTIEREN ('VOTE'), and stimmen ('VOTE') are among the most significant left-hand collocates of gegen, ${ }^{6}$ the translation equivalent of against. Verbs that express the meaning of PUSH ('DRüCKEN') or FALL ('FALLEN') tend to be used without or with a different preposition (DRüCKEN auf, put pressure on; FALLEN in/auf/von, FALL in/on/off). Learners'verb responses appear to be influenced by collocational preferences in their L1, providing evidence in support of our Hypothesis 5.

Czech learners show similar patterns of overlap and semantic preference as German learners. They share 9 verbs (out of 20) with the native speakers and have a strong preference for verbs that express a (verbal) reaction against something, including FIGHT (rank 1), SPEAK (rank 3), VOTE (rank 6), PROTEST (rank 10), and ARGUE (rank 11). Proti, the Czech translation equivalent of against, strongly collocates with verbs that express negative attitudes and evokes a sense of "reacting against" an opponent or enemy. Compared to the group of native speakers, fewer learners in the Czech group associate verbs such as LEAN, PUSH, or SIT with this VAC frame. These verbs are also infrequent in the L1 Spanish verb list. Between zero and four Spanish learners produce verbs of physical contact or collision when they are presented with a ' $\mathrm{V}$ against $\mathrm{n}$ ' frame. The two top responses from this group are forms of the verbs FIGHT and BE which together account for 71 or $54.2 \%$ of all participant responses. Again, L1 transfer may explain the strong association between FIGHT and against. In a large corpus of Spanish, the Corpus del Español, ${ }^{7}$ LUCHAR (FIGHT) was found to be by far the most frequent collocate immediately to the left of contra (against). This constitutes additional evidence in support of our Hypothesis 5.

\section{Zooming in on ' $V$ in $N$ '}

The correlation values for ' $\mathrm{V}$ in $\mathrm{n}$ ' vary considerably across learner groups. Correlations are high for German (0.79), slightly above average for Czech (0.69), and extremely low for Spanish (0.35). We hence expect strong overlap in terms of verb preferences between native speaker and German and Czech learner responses. We expect the verb choices of Spanish learners to be rather different from those of native speakers and from those of their German and Czech peers. Table 4 shows lemmatized lists of the 20 most frequent verbs produced by the four groups of survey participants in response to the prompts 'he in the ...' and 'it in the ....' The native speaker responses in the left-hand column (shaded gray) serve as a reference point for comparisons with the German, Czech, and Spanish learner responses. Verbs are italicized in a learner list if they also appear in the native speaker list.

Indeed, for this VAC, we observe much more overlap between native speaker and German (13 verbs) and native speaker and Czech (14 verbs) top-20 lists than between native speaker and Spanish lists (7 verbs), further confirming $\mathrm{Hy}-$ pothesis 1. This higher degree of overlap for German and Czech than for Spanish responses also became apparent in the graphs provided in Figure 3. The shared verbs do, however, occupy different ranks across lists and/or have quite different token frequencies. Although shared among the top 20, verbs that express static meanings (including BE, LIVE, STAY, and STAND) are more often produced by German and Czech learners than by native speakers. Several of the motion verbs produced by native speakers (GO, WALK, COME) have the same or similar frequencies in the German and (though to a lesser extent) Czech lists. Other motion verbs produced by native speakers (SLIDE, BLOW, DRAW, JUMP, SWIM) are absent from or less common in the German and Czech learner responses. Again we observe that learners produce verbs that have high frequencies in usage and have stronger associations with verbs that are common in general language use.

The Spanish learner responses are very different from both the native speaker and the German/Czech learner responses, providing further evidence in support of our Hypothesis 2. The scatterplot in Figure 3 already provided an illustration of this lack of overlap between Spanish 
TABLE 4

'V in n,' Top 20 Verbs in Native Speaker and Learner Responses

\begin{tabular}{|c|c|c|c|c|c|c|c|c|}
\hline \multirow{2}{*}{$\frac{\text { Rank }}{1}$} & \multicolumn{2}{|c|}{ Native Speakers } & \multicolumn{2}{|c|}{ German Learners } & \multicolumn{2}{|c|}{ Czech Learners } & \multicolumn{2}{|c|}{ Spanish Learners } \\
\hline & $\mathrm{BE}$ & 19 & $B E$ & 27 & $B E$ & 33 & $B E$ & 53 \\
\hline 2 & SIT & 15 & $S I T$ & 11 & $L I V E$ & 10 & LIVE & 9 \\
\hline 3 & JUMP & 10 & LIVE & 8 & STAND & 7 & STAY & 8 \\
\hline 4 & WALK & 8 & GO & 8 & $S I T$ & 7 & PLAY & 4 \\
\hline 5 & GO & 7 & WALK & 8 & WAIT & 6 & SLEEP & 3 \\
\hline 6 & LOOK & 6 & HIDE & 5 & WORK & 5 & HIDE & 3 \\
\hline 7 & FALL & 6 & STAND & 5 & COME & 5 & COME & 3 \\
\hline 8 & COME & 4 & LOOK & 4 & SLEEP & 4 & STAND & 3 \\
\hline 9 & LIVE & 4 & SLEEP & 3 & STAY & 4 & PUT & 3 \\
\hline 10 & SING & 3 & COME & 3 & PARTICIPATE & 3 & WORK & 2 \\
\hline 11 & RUN & 3 & $F A L L$ & 3 & $F A L L$ & 3 & TRAVEL & 2 \\
\hline 12 & STAND & 3 & STAY & 3 & LIE & 3 & ENTER & 2 \\
\hline 13 & SWIM & 3 & WORK & 2 & $L O O K$ & 3 & ARRIVE & 2 \\
\hline 14 & HIDE & 3 & PARTICIPATE & 2 & $G O$ & 3 & GET & 2 \\
\hline 15 & SLEEP & 3 & STUDY & 2 & WALK & 3 & FILL & 2 \\
\hline 16 & SLIDE & 2 & WAIT & 2 & HIDE & 2 & REMAIN & 2 \\
\hline 17 & DRAW & 2 & BITE & 2 & SWIM & 2 & GO & 2 \\
\hline 18 & LIE & 2 & SEARCH & 2 & PUT & 2 & EAT & 2 \\
\hline 19 & READ & 2 & $R U N$ & 2 & $J U M P$ & 2 & INVOLVE & 1 \\
\hline 20 & BLOW & 2 & $J U M P$ & 2 & RELAX & 1 & STUDY & 1 \\
\hline
\end{tabular}

Note. Italicized verbs indicate overlap between a learner list and the native speaker list.

learner and native speaker verb responses. Over $40 \%$ of Spanish survey participants (53 of 131) respond to the ' $\mathrm{V}$ in $\mathrm{n}$ ' prompt with forms of the most frequent, semantically bleached verb BE. They share their preference for LIVE and STAY with the German and Czech groups but largely avoid motion verbs. WALK, FALL, and JUMP are absent from the Spanish list while come and Go are rare. The strong differences between native speaker and Spanish learner responses likely are a result of the typological differences between English and Spanish that we discussed earlier. 'V in n' is one of many VACs in our set in which a path of motion is expressed by a satellite (here the preposition in). The verb-framed language Spanish tends to encode this path in the verb and the manner of motion in an adjunct, so walk in is realized as entrar caminando (enter walking). Hence, it is not surprising that our Spanish learners do not (or very rarely) produce verbs such as WALK, GO, FALL, or Jump in response to the ' $\mathrm{V}$ in $\mathrm{n}$ ' prompt.

\section{Zooming in on ' $V$ Over $n$ '}

For ' $\mathrm{V}$ over $\mathrm{n}$ ' we see a split in terms of correlation values between German (0.72) and Czech learners (0.76) on the one hand and Spanish learners $(0.48)$ on the other-similar to the ' $\mathrm{V}$ in $\mathrm{n}$ ' construction discussed in the previous section. Apparently, Spanish learners find it harder to produce target-like verbs than their Czech and German peers, again providing supportive evidence for Hypothesis 2. As in the case of ' $\mathrm{V}$ in $\mathrm{n}$,' this is likely related to L1-specific differences with respect to expressing path and manner of motion. Table 5 shows lemmatized lists of the 20 most frequent verbs produced by the four groups of survey participants in response to the prompts 'he in the ...' and 'it in the ....' The native speaker responses in the lefthand column (shaded gray) serve as a reference point for comparisons with the German, Czech, and Spanish learner responses. Verbs are italicized in a learner list if they also appear in the native speaker list.

The higher correlation figures observed for German and Czech learners are supported by a fairly high number of verbs that are shared across these two groups and the native speaker top 20 lists (11 for each group). JUMP, FALL, BE, RUN, GO, and LOOK are among the highest-ranking verbs in all three lists. Like native speakers, Czech and German learners associate over with verbs of directed motion. Compared to native speakers, Czech learners show a preference for FALL and RUN (16 and 12 compared to 9 responses); German learners more often respond with $\mathrm{GO}, \mathrm{BE}$, and cOME. This learner group also produces motion verbs (WALK, SWIM) that do not occur in the native 
TABLE 5

'V Over n,' Top 20 Verbs in Native Speaker and Learner Responses

\begin{tabular}{|c|c|c|c|c|c|c|c|c|}
\hline \multirow{2}{*}{$\frac{\text { Rank }}{1}$} & \multicolumn{2}{|c|}{ Native Speakers } & \multicolumn{2}{|c|}{ German Learners } & \multicolumn{2}{|c|}{ Czech Learners } & \multicolumn{2}{|c|}{ Spanish Learners } \\
\hline & JUMP & 29 & JUMP & 22 & JUMP & 23 & GET & 13 \\
\hline 2 & FALL & 10 & $F A L L$ & 13 & $F A L L$ & 17 & COME & 13 \\
\hline 3 & RUN & 9 & GO & 13 & $R U N$ & 12 & $B E$ & 13 \\
\hline 4 & GO & 9 & $B E$ & 10 & GO & 7 & TAKE & 12 \\
\hline 5 & CLIMB & 7 & WALK & 10 & LOOK & 6 & GO & 12 \\
\hline 6 & $\mathrm{BE}$ & 6 & COME & 9 & COME & 5 & $L O O K$ & 10 \\
\hline 7 & FLY & 5 & LOOK & 9 & $B E$ & 5 & $R U N$ & 5 \\
\hline 8 & LOOK & 5 & $R U N$ & 7 & CLIMB & 5 & $F L Y$ & 4 \\
\hline 9 & HOP & 4 & BEND & 4 & WALK & 4 & CROSS & 4 \\
\hline 10 & ROLL & 4 & ROLL & 3 & GET & 3 & $F A L L$ & 4 \\
\hline 11 & DRIVE & 3 & $F L Y$ & 2 & ROLL & 3 & TURN & 3 \\
\hline 12 & COME & 3 & SWIM & 2 & BEND & 3 & BEND & 3 \\
\hline 13 & READ & 3 & LIE & 2 & CROSS & 3 & WALK & 3 \\
\hline 14 & LEAP & 3 & SIT & 2 & SLEEP & 2 & LEAN & 3 \\
\hline 15 & STEP & 2 & SLEEP & 1 & CALL & 2 & $J U M P$ & 2 \\
\hline 16 & CROSS & 2 & SHIN & 1 & SAIL & 2 & WORK & 1 \\
\hline 17 & SLEEP & 1 & LEAVE & 1 & TURN & 2 & TRAVEL & 1 \\
\hline 18 & CYCLE & 1 & JULPED & 1 & TAKE & 2 & OVER & 1 \\
\hline 19 & AIR & 1 & LIVE & 1 & TRIP & 2 & MIND & 1 \\
\hline 20 & PUSH & 1 & WRITE & 1 & THINK & 2 & DANCE & 1 \\
\hline
\end{tabular}

Note. Italicized verbs indicate overlap between a learner list and the native speaker list. The form julped (number 18 in the L1 German list) presumably resulted from a learner's attempt to type the form jumped.

speaker response list, and for which the preposition across may be a better, more idiomatic fit (swim across instead swim over). The reason for this may be L1 transfer. German learners may find it difficult to distinguish between over and across because both share the same translation equivalent: über. Neither learner group includes any of the more specific motion verbs in their responses that native speakers associate with this VAC (e.g., HOP, DRIVE, LEAP, STEP, PUSH, Or CYCLE). These are verbs that are strongly associated with the construction in language use but of lower overall frequency and less accessible to German/Czech learners.

This is also true for the Spanish learners who participated in the survey. None of the more specific motion verbs (HOP, DRIVE, etc., plus CLIMB) appear in their list of top 20 verb responses. The verb at the top of the Spanish frequency list is GET, which does not appear at all in the native speaker or German responses and is infrequent in the Czech responses. This verb is followed by COME, BE, and TAKE-all of which are much less common in the native speaker list (TAKE does not occur at all). It appears that Spanish learners associate with over constructions not primarily the expression of a directed motion but instead think of metaphorical uses such as get over and take over. Particularly striking in this context is the fact that only 2 Spanish participants responded with JUMP whereas this is the most frequent verb in the native speaker, German, and Czech learner lists (with 29, 22, and 23 instances, respectively). As mentioned earlier, jump over is not realized by a verb plus preposition in Spanish (but it is in German and can be in Czech). ${ }^{8}$ Instead, Spanish uses the verb SALTAR, which encodes the path of motion. This may be why JuMP is so infrequent in the Spanish learner responses. The same applies to climb over which can be translated as SALTAR (escalando) or TREPAR. This further supports our Hypotheses 2 and 4 and confirms our assumption that the low correlation of Spanish learner and native speaker responses to the ' $\mathrm{V}$ over $\mathrm{n}$ ' frame may be due to issues of language typology that are related to different strategies of expressing motion.

\section{CONCLUSION AND OUTLOOK}

This article set out to examine L2 language learners' knowledge of verb-argument constructions (VACs). In psycholinguistic experiments, we gathered evidence on L1 German, L1 Czech, and L1 Spanish advanced English learners' mental representations of 19 different VACs. A comparison of data from these experiments with data collected from native English speakers performing the same task allowed us to determine how similar or different learners' verb-VAC associations are from those of native speakers. The 
experiments enabled us to highlight verbs (or groups of verbs) that are more entrenched in native speakers' than in learners' mental representations of particular VACs, and vice versa.

With respect to our Research Question 1, we found that, while there is some overlap between learners' and native speakers' mental representations of VACs (also see our discussion in Ellis et al., 2014b), there are also differences in the associations of verbs and constructions. We observed that all three learner groups rely more on general, highly frequent verbs (e.g., BE, COME, Do) and produce lower numbers of specific, less frequent verbs (e.g., SLIP, REACH, CRAWL) than native speakers do. We also observed that, for certain VACs, learners' semantic associations with a VAC are different from native speakers. For example, learners associate verbs that express a reaction or argument (including FIGHT, ARGUE, and SPEAK) with 'V against n' while native speakers associate verbs of physical contact or collision (e. g., LEAN, PUSH, and BUMP) with this VAC.

In response to Research Question 2, we found that, in their verb-VAC associations, our three groups of learners are not equally different from the native speaker group but that L1 German and L1 Czech learners are closer to the native speaker group than L1 Spanish learners. In an overview chapter of studies that provide empirical evidence for language typology effects on linguistic production, Cadierno (2008) asks "how do L2 learners with typologically different L1s and L2s acquire the characteristic meaning-form mappings of the L2? And how does the performance of this type of learner compare to learners whose L1 and L2 share the same typological patterns?" (p. 258). We have addressed these questions with reference to learners' knowledge of English verbargument constructions. We found that, for most of the 19 VACs we examined, the mappings of L1 German and L1 Czech learners (i.e., speakers of languages that share the same typological pattern as English) are more target-like than those of L1 Spanish learners (i.e., speakers of a language that is typologically different from English). While all three groups of learners have developed constructional knowledge, the overlap with native speaker verb-VAC associations is generally greater for German and Czech than for Spanish learners.

This brings us back to Research Question 3, which asked whether differences across L2 learner groups could be explained on the basis of L1 transfer and/or language typology effects. We think the answer to this question is yes. Spanish learners, more than German and Czech learners, favored general motion verbs in their survey responses and avoided specific manner of motion verbs. Spanish learners also produced the highest numbers of non-target-like verbs in response to VACs that encode a path of motion in the preposition (e.g., 'V over n' and 'V against $n$ '). Based on these observations, we believe that a major factor that influences the level of target-like form-meaning mapping of common English VACs is language typology or, more precisely, the type of motion event conceptualization across languages. Fewer manner of motion verbs are produced by Spanish learners who in turn struggle more with VACs that encode a path, because Spanish is a verb-framed language in which manner of motion verbs are less readily available and in which the path of motion tends to be encoded in the verb. Given that patterns of expressing motion are language type specific, the challenge for the language learner is to acquire the respective patterns for each new language. As our results indicate, this becomes harder when the new/second language is typologically different from the learner's first language. Echoing observations previously made on learned attention and SLA (Ellis \& Sagarra, 2011), we can say that a learner's L1 and the L1-tuned expectations that come with it bias her/his system and, depending on how typologically similar or different the L1 and L2 are, make her/him more or less open to internalizing structures in the L2. Further addressing the crosslinguistic transfer issue ( $\mathrm{Hy}-$ pothesis 5), we also found evidence of verbpreposition combinations in the learner survey data that are likely the result of collocational transfer from the L1s of the learners. An example was German learners' association of FIGHT, PROTEST, and VOTE with the 'V against $\mathrm{n}$ ' constructions -all verbs that strongly collocate with the translation equivalent of against (gegen) in German. Similar effects were observable in the Czech and Spanish learner survey results. Searches in corpora of the learners' L1s helped us confirm our assumptions.

We also considered language proficiency as a potential factor that may have influenced our results. Given that the majority of learners who participated in our study were at the same advanced level of proficiency (CEFR level C1), we can disregard this as an influential factor. The small number of level B2 learners among the L1 Spanish group (around 10 of the 131 participants) is unlikely to have had a major effect on the overall results. The Spanish learners who participated in our study also reported longer times of having had English instruction at school than German and Czech learners (an average of 
12.68 years, compared to 10.04 years for German and 11.37 for Czech).

We have been able to confirm all of the research hypotheses formulated earlier: The mental VAC representations of German, Czech, and Spanish advanced learners of English differ in diverse ways from those of native speakers, indicating that learners are biased by their L1s. In generative free association tasks, learners whose L1 is satelliteframed (and hence typologically similar to English) produce more verbs that correlate more closely with those produced by L1 English speakers than speakers whose L1 is verb-framed. Speakers of a satellite-framed language produce more verbs that express specific manners of motion in the verb generation tasks. Conversely, speakers of a verb-framed language produce specific manner of motion verbs less frequently and instead respond with more general motion verbs such as GO, COME, or move. Lastly, the verb responses of all learner groups show effects of collocational transfer from the learners' first languages.

Our findings have implications for language teaching and for research in SLA. Second language instruction needs to acknowledge the pervasiveness of constructions more than it currently does. With few exceptions, current EFL and ESL textbooks are still largely based on models of language that suggest a strict separation of lexis and grammar and fail to reflect the interconnectedness of the two (see e.g., Meunier \& Gouverneur, 2007; Römer, 2005, 2007). We suggest that materials focus more on typical associations of lexical items and constructions and emphasize patterns in form-meaning relations. Constructions that are semantically related (e.g., VACs expressing directed motion) could be grouped and taught together. That way, as Littlemore (2011) points out, it may be possible for learners to "use their existing knowledge of constructions to infer the meanings of ones that are new to them" (p. 171). At the same time, it needs to be highlighted which meanings are most typically construed by which construction and what the most common lexical items are in each construction. It may also be necessary to make learners aware of differences between VACs in their L1 and the L2. Learners of L1s that are typologically different from English (such as Spanish, covered in our study) may need additional help with specific constructions for which their form-meaning mappings are less target-like. Our findings could help raise instructors' and materials writers' awareness of learners' most entrenched verb-VAC associations and how they differ from those of native speakers. Learners' restructuring of form-meaning associations takes time, and it needs a lot of exposure to natural language use-ideally in the form of "extensive interaction in a variety of contexts with members of the target language community" (Jarvis \& Pavlenko, 2008, p. 152). We find some of the recent research in applying Cognitive Linguistics to teaching English modals and prepositions particularly promising and inspiring (see e.g., Tyler, 2012; Tyler, Mueller, \& Ho, 2011) and believe that the teaching of VACs could benefit from a similar approach.

In our SLA research agenda, we need to include related work on an even larger set of constructions, including speakers of additional L1 backgrounds, and collecting larger and richer data sets. We have begun to gather responses to additional VAC frames from native speakers and German and Spanish learners. From the same groups of learners, we have also begun to collect richer data in verbal production tasks that ask participants to generate as many verbs as they can think of in one minute (following the methodology suggested in Ellis et al., 2014a; see also Cadierno, 2010). It would also be interesting to collect data from learners at additional proficiency levels. A concern here, however, would be that the type of task we used in our study may be too difficult for beginning or intermediate learners (L1 Spanish learners at CEFR level B1 who were given the survey as a test struggled with the gap-fill task and gave up after looking at the first few prompts). Additional evidence on learner VAC knowledge could come from analyses of learner corpora which capture the output of learners of different L1s and at different proficiency levels. We are currently mining subsets of written and spoken corpora of advanced learner English, the International Corpus of Learner English (ICLE; Granger et al., 2009) and the Louvain International Database of Spoken English Interlanguage (LINDSEI; Gilquin, De Cock, \& Granger, 2010) for VACs. Initial results of these learner corpus analyses are discussed in Römer, Roberseon, O'Donnell, \& Ellis (2014). One thing that our initial ICLE and LINDSEI explorations highlight is that L1-specific subsets of these two learner corpora provide robust token numbers for some VACs (e.g., 'V in n' and 'V about n') but are too small to give us enough tokens of the majority of VACs in our sample to identify semantic patterns or even lead verbs. This calls for larger corpora of learner production that are carefully differentiated and marked up with learner metadata (like ICLE and LINDSEI are). Longitudinal learner corpora that consist of 
learner data at different proficiency levels and allow us to capture learners' language development would also be extremely valuable in this context. As convincingly pointed out by Byrnes (2009) in a study of the emergent writing ability of L2 German learners, the adoption of a "developmental view has the potential of capturing the dynamic nature of language use, language development, and the language system" (p. 64).

In this article, we have taken a snapshot of part of the linguistic knowledge of three groups of advanced English language learners. Our study has provided evidence for representations of a set of verb-argument constructions in the minds of these learners. It has highlighted which verbs learners most strongly associate with these constructions and how their associations differ from those of native speakers. We believe that this snapshot has helped us gain a better understanding of what speakers know about verbs in constructions and of the role that language typology and language transfer play in this context.

\section{ACKNOWLEDGMENTS}

We would like to thank contacts at the following universities who helped with survey participant recruitment by distributing the survey link: University of Cologne (Germany), University of Giessen (Germany), University of Hanover (Germany), University of Heidelberg (Germany), University of Oldenburg (Germany), University of Trier (Germany), Masaryk University (Czech Republic), Charles University (Czech Republic), University of Extremadura (Spain), University of Granada (Spain), University of Jaen (Spain), University Jaume I of Castellon (Spain), University of Salamanca (Spain), and University of Zaragoza (Spain). We are also grateful to Markéta Malá for her native speaker advice on Czech translation equivalents of "jump over," to Petr Sudický for his help with interpreting some of the L1 Czech learner responses, and to Paco Barrón Serrano for his help with interpreting some of the L1 Spanish learner responses.

\section{NOTES}

${ }^{1}$ http://www.qualtrics.com, last accessed 12 April 2014.

${ }^{2}$ We decided to exclude ' $\mathrm{V}$ at $\mathrm{n}$ ' from further analyses because we were unable to get reliable results (in terms of search precision) in the corpus mining, which constitutes a central component in the comparative part of the knowledge study described in Ellis et al. (2014a).
${ }^{3}$ Lemmatization was carried out using the morphy function in the WordNet dictionary implemented in the Natural Language Toolkit (NLTK). The function uses a series of suffix rules based on part-of-speech category (e. g., $\mathrm{V}=$ verb, $\mathrm{N}=$ noun) and an exception (i.e., irregular forms) lookup list (see http://wordnet.princeton.edu/ man/morphy.7WN.html for details, last accessed 12 April 2014) and attempts to find the base form (lemma) in WordNet that matches the supplied form. If a match cannot be made the supplied form is returned. For example: running $(\mathrm{V})>$ run; running $(\mathrm{N})>$ running, ran (V) > run; ran $(\mathrm{N})>$ ran. This matching strategy does not use frequency or probabilistic data to select base forms from WordNet, yielding some unexpected results. For instance, there is a verb lemma fell ('cause to fall by or as if by delivering a blow,' e.g., 'the woodcutter felled the tree'), which leads to these results: $f$ fell $(\mathrm{V})>$ fell; felled $(\mathrm{V})>$ fell; falls $(\mathrm{V})>$ fall; falling $(\mathrm{V})>$ fall. In the verb completion experiment fell was provided in response to a number of frames such as 's/he/it___ across the ...,' and with among, against, between, for, of, over, through, and towards. Forms of fall (fall, falls, falling) were also provided with these frames. As a result, we end up with two items in the initial frequency lists. We merged instances of fall and fell and lay and lie into two lemmas and also searched for other similar items in our lists that may have homonyms in WordNet.

${ }^{4}$ See Gries and Deshors (2014) and Gries and Adelman (2014) for examples of using regression to examine the relationships between NS and NNS usage of linguistic features. These articles argue for a more involved use of regression analysis and use multivariate and multilevel approaches.

${ }^{5}$ The average numbers of verb types produced per VAC were 40.6 for L1 German, 34.0 for L1 Czech, and 37.4 for L1 Spanish learners. Native speaker participants produced an average of 45.1 different verbs per VAC.

${ }^{6}$ Source: DWDS (Das digitale Wörterbuch der deutschen Sprache), a corpus-based dictionary of German. URL of the search: http://www.dwds.de/?qu=gegen, last accessed 12 April 2014. Selected collocate statistic: Mutual Information (MI).

${ }^{7}$ http://www.corpusdelespanol.org/, last accessed 12 April 2014.

${ }^{8}$ As mentioned in the section on language typology, translation equivalents of jump over in Czech include skočit pres ('jump over'), preskočit pres ('overjump over'), and preskočit ('overjump').

\section{REFERENCES}

Battig, W. R., \& Montague, W. E. (1969). Category norms for verbal items in 56 categories: A replication and extension of the Connecticut category norms. Journal of Experimental Psychology, 80, 1-46.

Brown, A., \& Gullberg, M. (2011). Bidirectional crosslinguistic influence in event conceptualization? Expressions of path among Japanese learners of English. Language and Cognition, 14, 79-94. 
Bybee, J. L. (2006). From usage to grammar: The mind's response to repetition. Language, 82, 711-733.

Bybee, J. L. (2010). Language, usage, and cognition. Cambridge: Cambridge University Press.

Byrnes, H. (2009). Emergent L2 German writing ability in a curricular context: A longitudinal study of grammatical metaphor. Linguistics and Education, $20,50-66$.

Cadierno, T. (2008). Learning to talk about motion in a foreign language. In P. Robinson \& N. C. Ellis (Eds.), Handbook of cognitive linguistics and second language acquisition (pp. 239-275). London: Routledge.

Cadierno, T. (2010). Motion in Danish as a second language: Does the learner's L1 make a difference? In Z.-H. Han \& T. Cadierno (Eds.), Linguistic relativity in second language acquisition: Thinking for speaking (pp. 1-33). Clevedon, UK: Multilingual Matters.

Cadierno, T. (2013). Thinking for speaking in second language acquisition. In C. A. Chapelle (Ed.), The encyclopedia of applied linguistics. Malden, MA: Wiley-Blackwell. Accessed 12 April 2014 at http://onlinelibrary.wiley.com/doi/10.1002/ 9781405198431.wbeal1213/full

Cifuentes-Férez, P., \& Gentner, D. (2006). Naming motion events in Spanish and English. Cognitive Linguistics, 17, 443-462.

Collins, L., \& Ellis, N. C. (2009). Input and second language construction learning: Frequency, form, and function. Modern Language Journal, 93, 329335 .

Council of Europe. (2001). Common European framework of reference for languages: Learning, teaching, assessment. Cambridge: Cambridge University Press. Accessed 16 April 2014 at http://www.coe.int/t/ dg4/linguistic/Source/Framework_EN.pdf

Ellis, N. C. (1998). Emergentism, connectionism and language learning. Language Learning, 48, 631664.

Ellis, N. C. (2002). Frequency effects in language processing: A review with implications for theories of implicit and explicit language acquisition. Studies in Second Language Acquisition, 24, 143-188.

Ellis, N. C. (2003). Constructions, chunking, and connectionism: The emergence of second language structure. In C. Doughty \& M. H. Long (Eds.), Handbook of second language acquisition (pp. 33-68). Oxford, UK: Blackwell.

Ellis, N. C. (2006). Selective attention and transfer phenomena in SLA: Contingency, cue competition, salience, interference, overshadowing, blocking, and perceptual learning. Applied Linguistics, 27, 164-194.

Ellis, N. C., \& Cadierno, T. (2009). Constructing a second language. Annual Review of Cognitive Linguistics, 7, Special section, 111-290.

Ellis, N. C., \& Ferreira-Junior, F. (2009). Constructions and their acquisition: Islands and the distinctiveness of their occupancy. Annual Review of Cognitive Linguistics, 7, 111-139.
Ellis, N. C., O’Donnell, M. B., \& Römer, U. (2013). Usage-based language: Investigating the latent structures that underpin acquisition. Language Learning, 63 (Supplement 1), 25-51.

Ellis, N. C., O'Donnell, M. B., \& Römer, U. (2014a). The processing of verb-argument constructions is sensitive to form, function, frequency, contingency, and prototypicality. Cognitive Linguistics, 25, 5598.

Ellis, N. C., O’Donnell, M. B., \& Römer, U. (2014b). Second language processing of verb-argument constructions is sensitive to form, function, frequency, contingency, and prototypicality. Linguistic Approaches to Bilingualism.

Ellis, N. C., \& Sagarra, N. (2011). Learned attention in adult language acquisition: A replication and generalization study and meta-analysis. Studies in Second Language Acquisition, 33, 589624.

Francis, G., Hunston, S., \& Manning, E. (Eds.). (1996). Collins COBUILD grammar patterns 1: Verbs. London: Harper Collins.

Gehrke, B. (2008). Ps in motion. On the semantics and syntax of $P$ elements and motion events. Utrecht, the Netherlands: LOT Publications. Accessed 12 April 2014 at http://www.lotpublications.nl/publish/ issues/Gehrke/index.html

Gilquin, G., De Cock, S., Granger, S (Eds.). (2010). LINDSEI: Louvain International Database of Spoken English Interlanguage. Louvain-la-Neuve, Belgium: Presses Universitaires de Louvain.

Goldberg, A. E. (1995). Constructions: A construction grammar approach to argument structure. Chicago, IL: University of Chicago Press.

Goldberg, A. E. (2003). Constructions: A new theoretical approach to language. Trends in Cognitive Science, 7, 219-224.

Goldberg, A. E. (2006). Constructions at work: The nature of generalization in language. Oxford: Oxford University Press.

Goldberg, A. E., Casenhiser, D. M., \& Sethuraman, N. (2004). Learning argument structure generalizations. Cognitive Linguistics, 15, 289-316.

Granger, S., Dagneaux, E., Meunier, F., \& Paquot, M. (Eds.). (2009). ICLE: International Corpus of Learner English. Louvain-la-Neuve, Belgium: Presses Universitaires de Louvain.

Gries, S. T., \& Adelman, A. S. (2014). Subject realization in Japanese conversation by native and nonnative speakers: Exemplifying a new paradigm for learner corpus research. In J. Romero-Trillo (Ed.), Yearbook of corpus linguistics and pragmatics. New York/Berlin: Springer.

Gries, S. T., \& Deshors, S. (2014). Using regressions to explore deviations between corpus data and a standard/target: Two suggestions. Corpora, 9, 109136.

Hunston, S., \& Francis, G. (2000). Pattern grammar: A corpus driven approach to the lexical grammar of English. Philadelphia/Amsterdam: John Benjamins. 
Ibbotson, P. (2013). The role of semantics, pre-emption and skew in linguistic distributions: The case of the un-construction. Frontiers in Psychology, 4, 989. Accessed 21 April 2014 at http://www.ncbi.nlm. nih.gov/pmc/articles/PMC3872292/

Jarvis, S. (2013). Crosslinguistic influence and multilingualism. In C. A. Chapelle (Ed.), The encyclopedia of applied linguistics. Malden, MA: Wiley-Blackwell. Accessed 12 April 2014 at http://onlinelibrary. wiley.com/doi/10.1002/9781405198431. wbeal0291/full

Jarvis, S., \& Pavlenko, A. (2008). Crosslinguistic influence in language and cognition. London: Routledge.

Littlemore, J. (2011). Applying cognitive linguistics to second language learning and teaching. Basingstoke, UK: Palgrave Macmillan.

MacWhinney, B. (2001). Emergentist approaches to language. In J. Bybee \& P. Hopper (Eds.), Frequency and the emergence of linguistic structure (pp. 449-470). Philadelphia/Amsterdam: John Benjamins.

Mani, I., \& Pustejovski, J. (2012). Interpreting motion: Grounded representations for spatial language. Oxford: Oxford University Press.

Meunier, F., \& Gouverneur, C. (2007). The treatment of phraseology in ELT textbooks. In E. Hidalgo, L. Quereda, \& J. Santana (Eds.), Corpora in the foreign language classroom (pp. 119-140). Amsterdam: Rodopi.

Odlin, T. (2013). Crosslinguistic influence in second language acquisition. In C. A. Chapelle (Ed.), The encyclopedia of applied linguistics. Malden, MA: Wiley-Blackwell. Accessed 12 April 2014 at http://onlinelibrary.wiley.com/doi/10.1002/ 9781405198431.wbeal0292/full

R Development Core Team. (2012). R: A language and environment for statistical computing. Vienna, Austria: R Foundation for Statistical Computing. Accessed 12 April 2014 at http://www.R-project. org/

Robinson, P., \& Ellis, N. C. (Eds.). (2008). Handbook of cognitive linguistics and second language acquisition. London: Routledge.

Römer, U. (2005). Progressives, patterns, pedagogy. A corpus-driven approach to English progressive forms, functions, contexts and didactics. Philadelphia/Amsterdam: John Benjamins.

Römer, U. (2007). Learner language and the norms in native corpora and EFL teaching materials: A case study of English conditionals. In S. Volk-Birke \& J. Lippert (Eds.), Anglistentag 2006 Halle. Proceedings (pp. 355-363). Trier, Germany: Wissenschaftlicher Verlag Trier.

Römer, U. (2009). The inseparability of lexis and grammar: Corpus linguistic perspectives. Annual Review of Cognitive Linguistics, 7, 140-162.

Römer, U., O’Donnell, M. B., \& Ellis, N. C. (2015). Using COBUILD grammar patterns for a large-scale analysis of verb-argument constructions: Exploring corpus data and speaker knowledge. In N. Groom, M. Charles, \& S. John (Eds.), Corpora, grammar and discourse: In honour of Susan Hunston. Philadelphia/Amsterdam: John Benjamins.

Römer, U., Roberson, A., O’Donnell, M. B., \& Ellis, N. C. (2014). Linking learner corpus and experimental data in studying second language learners' knowledge of verb-argument constructions. ICAME Journal, 38, 115-135.

Rosch, E., \& Mervis, C. B. (1975). Cognitive representations of semantic categories. Journal of Experimental Psychology, 104, 192-233.

Sinclair, J. M. (1991). Corpus, concordance, collocation. Oxford: Oxford University Press.

Sinclair, J. M. (2004). Trust the text. Language, corpus and discourse. London: Routledge.

Slobin, D. I. (2003). Language and thought online: Cognitive consequences of linguistic relativity. In D. Gentner \& S. Goldin-Meadow (Eds.), Language in mind: Advances in the study of language and thought (pp. 157-192). Cambridge, MA: MIT Press.

Slobin, D. I. (2006). What makes manner of motion salient? Explorations in linguistic typology, discourse, and cognition. In M. Hickmann \& S. Robert (Eds.), Space in languages: Linguistic systems and cognitive categories (pp. 59-81). Philadelphia/ Amsterdam: John Benjamins.

Stubbs, M. (2001). Words and phrases. Corpus studies of lexical semantics. Oxford, UK: Blackwell.

Talmy, L. (1985). Lexicalization patterns: Semantic structure in lexical form. In T. Shopen (Ed.), Language typology and syntactic description: Grammatical categories and the lexicon (pp. 57-149). Cambridge: Cambridge University Press.

Talmy, L. (1991). Path to realization: A typology of event conflation. In L. A. Sutton, C. Johnson, \& R. Shields (Eds.), Proceedings of the seventeenth annual meeting of the Berkeley linguistics society (pp. 480 520). Berkeley, CA: Berkeley Linguistics Society.

Talmy, L. (2000). Towards a cognitive semantics, vol. 2: Typology and process in concept structuring. Cambridge, MA: MIT Press.

Tomasello, M. (2003). Constructing a language: A usagebased theory of language acquisition. Boston: Harvard University Press.

Trousdale, G., \& Hoffmann, T. (Eds.). (2013). Oxford handbook of construction grammar. Oxford: Oxford University Press.

Tyler, A. (2012). Cognitive linguistics and second language learning: Theoretical basis and experimental evidence. New York: Routledge.

Tyler, A., Mueller, C., \& Ho, V. (2011). Applying cognitive linguistics to learning the semantics of English prepositions to, for, and at: An experimental investigation. VIGO International Journal of Applied Linguistics, 8, 180-205.

Yamashita, J., \& Jiang, N. (2010). L1 influence on the acquisition of L2 collocations: Japanese ESL users and EFL learners acquiring English collocations. TESOL Quarterly, 44, 647-668.

Zipf, G. K. (1935). The psycho-biology of language: An introduction to dynamic philology. Cambridge, MA: The M.I.T. Press. 


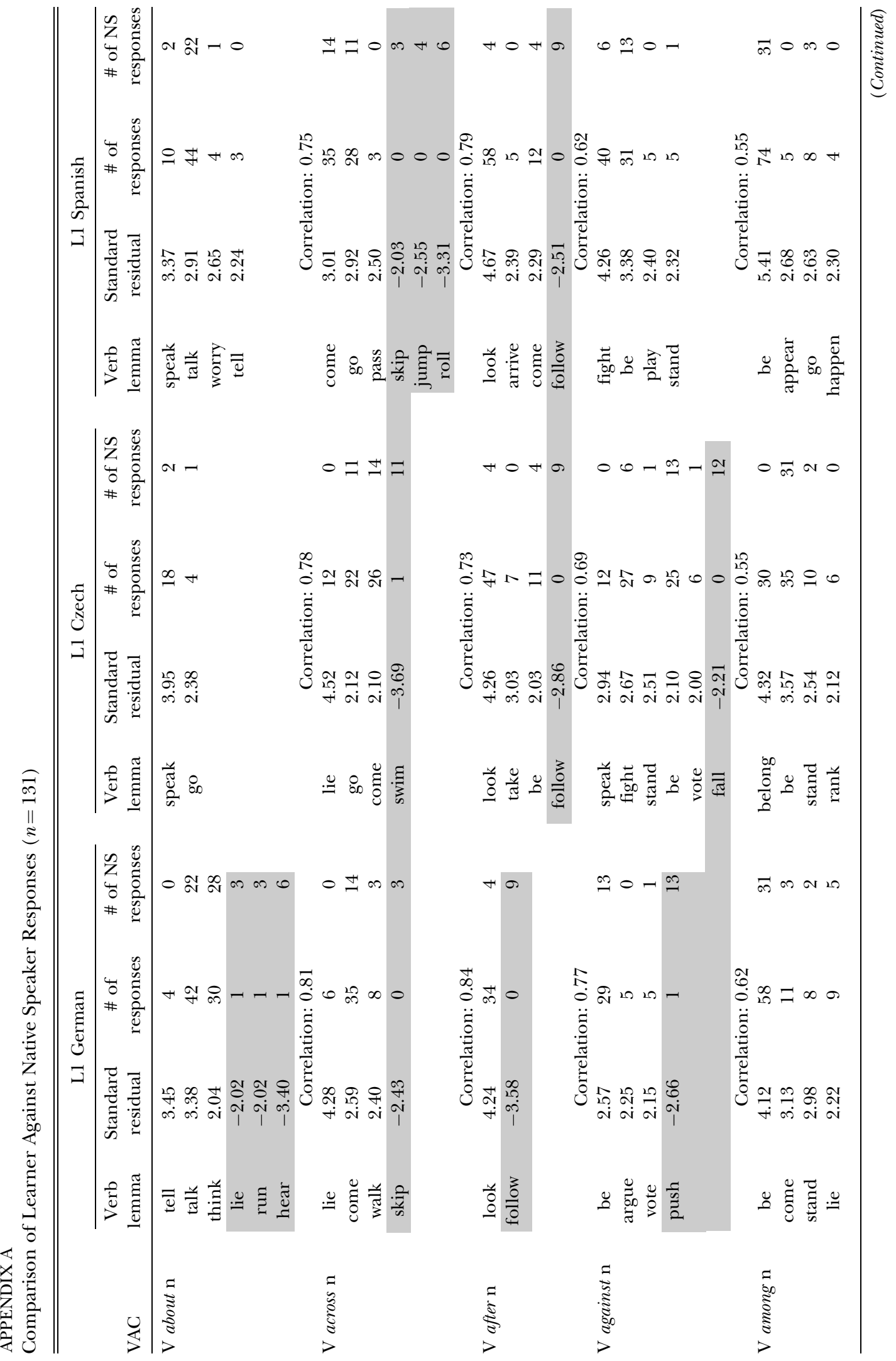




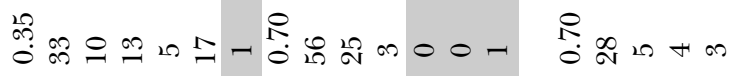
节

$\cos 0 \cos$ a tho ha a -00

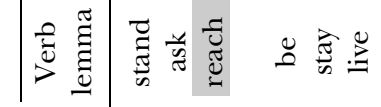

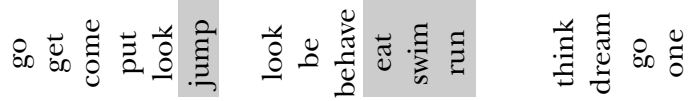

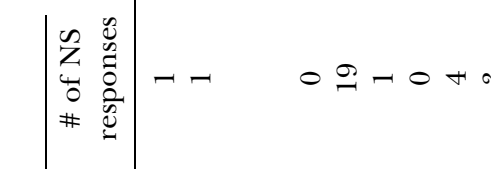

arano

$a-00$

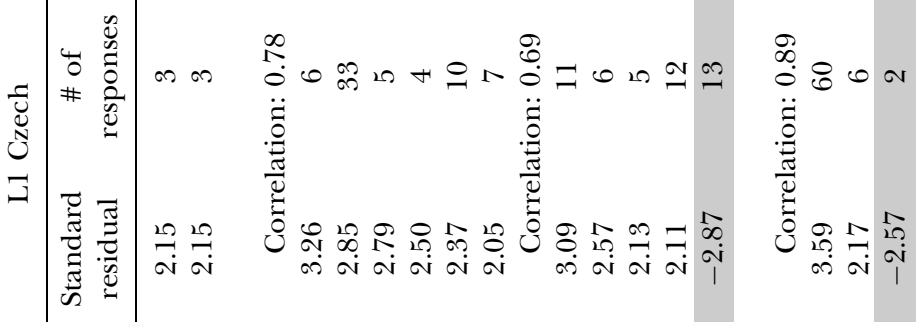

$\stackrel{\infty}{0} \bigcirc 0+-$

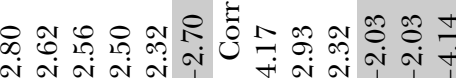

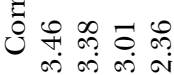

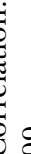

$8 \% \operatorname{loc}$ व ov ov

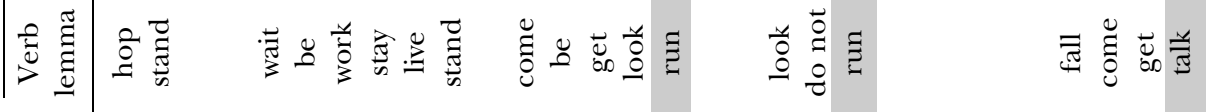

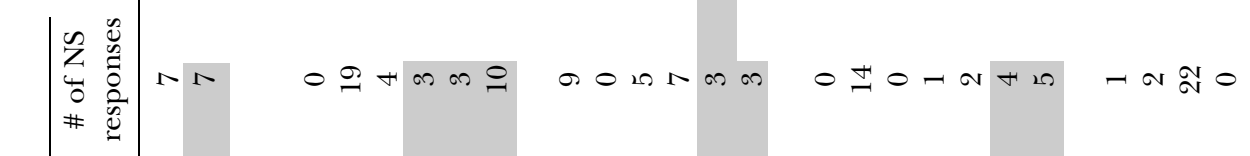

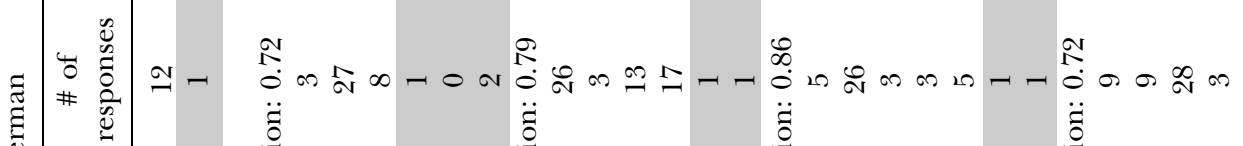
है

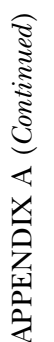

ב ت⿹

\section{苛}

嶑

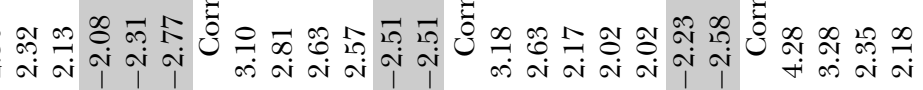




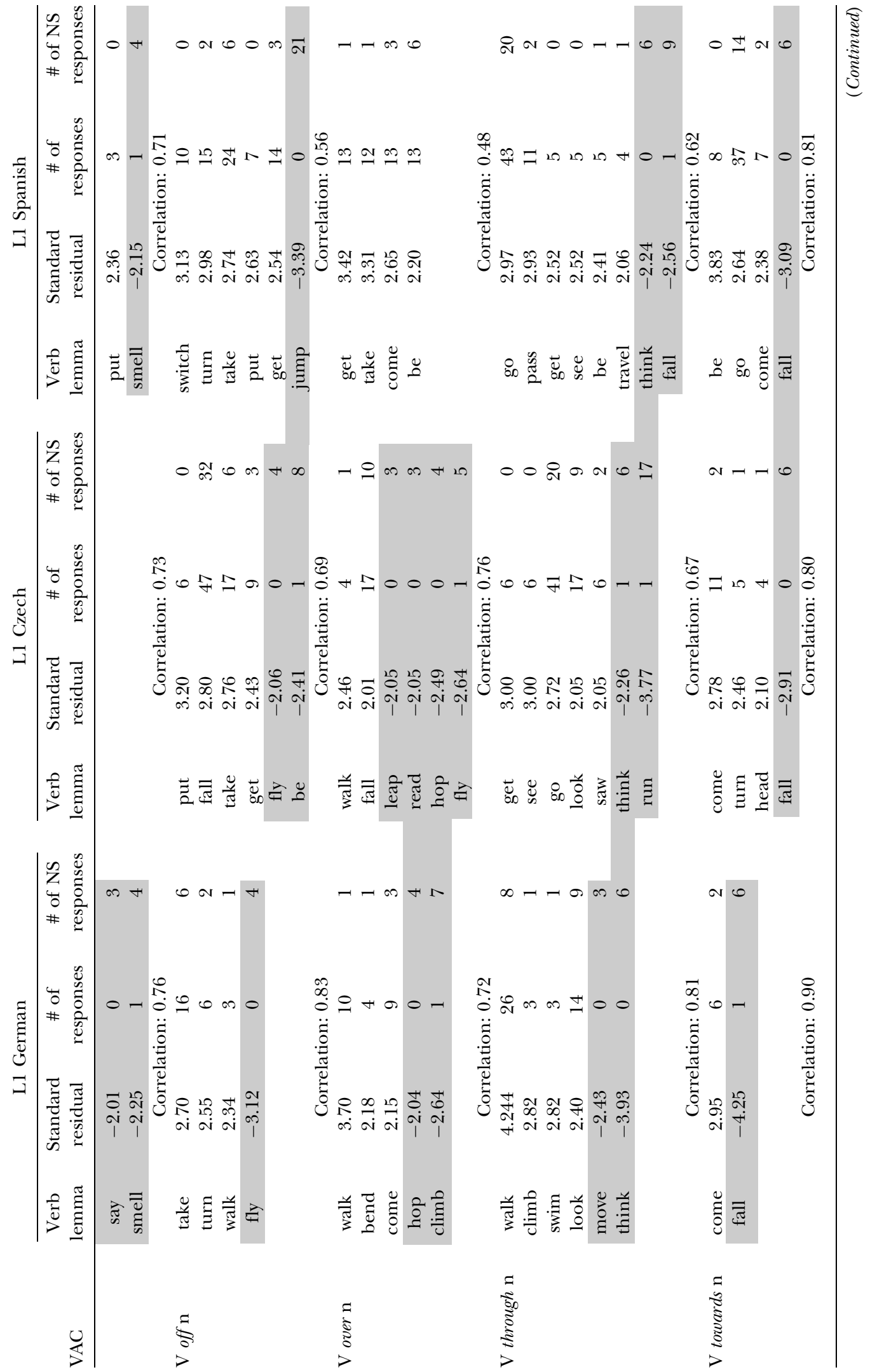


